\title{
Efectos del consumo de distintos niveles de semilla de algodón sobre las variables ruminales de novillos cruza cebú
}

\author{
Koza, G.A.'; Giménez, L. ${ }^{2}$; Rochinotti, D. ${ }^{3}$; Coppo, J.A. ${ }^{1}$ Mussart, N.B. ${ }^{1}$ \\ ${ }^{1}$ Cátedra de Fisiología, Facultad de Ciencias Veterinarias, UNNE, \\ Sargento Cabral 2139, Corrientes (3400), Argentina. Tel/fax 03794-425753. \\ ${ }^{2}$ INTA Corrientes. ${ }^{3}$ INTA Mercedes. E-mail: fisiologia@vet.unne.edu.ar
}

\begin{abstract}
Resumen
Koza, G.A.; Giménez, L.; Rochinotti, D.; Coppo, J.A.; Mussart, N.B.: Efectos del consumo de distintos niveles de semilla de algodón sobre las variables ruminales de novillos cruza cebú. Rev. vet. 26: 1, 3-12, 2015. La semilla de algodón (SA) constituye un recurso alimenticio importante para el ganado del nordeste argentino por su bajo costo y alto nivel nutritivo. El objetivo de este trabajo fue verificar los cambios provocados a nivel ruminal por la inclusión de SA, dado su elevado contenido lipídico. Empleando un diseño cuadrado latino balanceado, se dispuso de cuatro novillos cruza cebú con fístula ruminal, los cuales fueron alimentados con heno de Cynodon nlemfuensis y suplementados con diferentes niveles de SA, constituyendo los tratamientos: bajo $(0,6 \mathrm{~kg})$, medio $(1,2 \mathrm{~kg})$, alto $(1,8 \mathrm{~kg})$ y cero (sin SA). La experiencia abarcó 84 días (cuatro períodos de 21 días), durante los cuales se registró el consumo de heno. Las muestras de rumen se extrajeron a diferentes horas post-suplementación para valorar $\mathrm{pH}$, ácidos grasos volátiles (AGV) y protozoarios. Los cálculos estadísticos incluyeron técnicas descriptivas, medidas repetidas, contrastes ortogonales (efectos lineales, cuadráticos y cúbicos) y comparaciones de medias. Se concluye que la concentración de AGV totales no fue afectada, pero se constataron aumentos de propionato, disminuciones de acetato e invariabilidad del isobutirato. El butirato se elevó en los niveles bajo y medio. Valerato e isovalerato aumentaron por el suministro de SA. El caprionato declinó en el tratamiento alto, incrementándose en el bajo. El amonio ruminal registró una elevación lineal paralela a la cantidad de SA ingerida. El pH no varió en ningún tratamiento. Los protozoarios totales disminuyeron en función del aumento de SA. Entodinium prevaleció en todos los tratamientos, Dasytricha, Isotricha y Ostracodinium predominaron en cero, Diplodinium en bajo y medio.
\end{abstract}

Palabras clave: novillo cruza cebú, semilla de algodón, pH ruminal, ácidos grasos volátiles, protozoarios.

\begin{abstract}
Koza, G.A.; Giménez, L.; Rochinotti, D.; Coppo, J.A.; Mussart, N.B.: Effects of different levels of cottonseed consumption on the ruminal variables of half-bred zebu steers. Rev. vet. 26: 1, 3-12, 2015. Cottonseed (SA) constitutes an important alimentary resource for livestock from Argentinean northeast due to its low cost and high nutritious level. The objective of this work was to verify the changes in the ruminal environment induced by the inclusion of SA, due to its high lipid concentration. Using a balanced latin square design, four half-bred zebu steers with ruminal fistula were used, which were fed on Cynodon nlemfuensis hay and supplemented with different levels of SA, constituting the treatments: low $(0.6 \mathrm{~kg})$, medium $(1.2 \mathrm{~kg})$, high $(1.8 \mathrm{~kg})$ and zero (without SA). The experience lasted 84 days (four periods of 21 days each). The consumption of hay was registered. Rumen samples were extracted at different times post-suplementación to determine $\mathrm{pH}$, volatile fatty acids (AGV) and protozoa. Statistical calculations included descriptive parameters, repeated measures, orthogonal contrasts (lineal, quadratic and cubic effects) and means comparison. It is concluded that total concentration of AGV was not affected, but propionate increase, acetate decrease, and invariability of the isobutirate were verified. Butirate raised for the low and medium levels. Valerate and isovalerate increased due to the supplementation of SA. Caprionate decreased in the high treatment, but increased in the low level. Ruminal ammonium registered a lineal elevation parallel to the quantity of ingested SA; the $\mathrm{pH}$ didn't vary in
\end{abstract}


any treatment. Total protozoa diminished in function to the increment of SA. Entodinium prevailed in all the treatments, Dasytricha, Isotricha and Ostracodinium prevailed in zero, Diplodinium in low and medium levels.

Key words: half-bred zebu steer, cottonseed, ruminal $\mathrm{pH}$, volatile fatty acids, protozoa.

\section{INTRODUCCIÓN}

El algodón es un cultivo industrial de gran preeminencia para las economías de la región extra pampeana de Argentina. Las provincias de mayor producción son Chaco y Santiago del Estero, superando entre ambas el $80 \%$ del total del país. La semilla de algodón (SA) es un alimento de elevado valor nutritivo para el ganado. Posee un buen balance entre proteína bruta (PB: 18 a 24\% de la materia seca, MS) y energía (3,5 Mcal de energía metabolizable/kg de MS). Presenta altos contenidos de fibra y energía, niveles moderados a altos de proteínas y es relativamente palatable para los bovinos ${ }^{19}$.

La adición de grasas a una ración con mala calidad de forraje puede elevar la densidad energética (calorías), incrementando la performance del animal y aumentando la ganancia de peso. La SA constituiría un buen suplemento para bovinos que consumen forrajes de mala calidad ${ }^{19}$. La semilla entera es la más usada como material alimenticio por contener mayor cantidad de fibra y energía; la fibra se halla en la cubierta que envuelve a la semilla ( $10 \%$ del peso de la semilla entera) con elevado porcentaje de celulosa y alta digestibilidad. La energía está contenida en el aceite que posee la semilla. La adición de SA entera o partida no afectaría la digestibilidad de la fibra de la pastura natural ${ }^{15}$. Para otros autores en cambio, la incorporación de esta oleaginosa, podría suscitar problemas de palatabilidad, con disminución de la digestibilidad de la fibra ${ }^{29}$.

En la zona, la SA es un recurso alimenticio importante por su bajo costo y buen valor nutritivo, haciendo que su empleo como suplemento sea una práctica común para cubrir el déficit invernal del campo natural y de las pasturas subtropicales cultivadas. Se ha investigado el efecto de distintos niveles de SA en la ración; los resultados obtenidos demostraron su efectividad como fuente nutricia, pero hasta el momento, no se conoce totalmente la forma en que el bovino utiliza este producto y su repercusión sobre el funcionamiento ruminal.

El objetivo del presente trabajo fue evaluar, en novillos cruza cebú con fístula ruminal, los efectos de la incorporación de diferentes niveles de SA sobre el ambiente ruminal $(\mathrm{pH}$, concentración de ácidos grasos volátiles $\mathrm{AGV}$, concentración de amoníaco y recuento de protozoarios).

\section{MATERIAL Y MÉTODOS}

Se empleó un diseño experimental cuadrado latino balanceado $4 \times 4$, donde cada animal constituyó una unidad experimental, de la cual se obtuvieron las muestras estipuladas. Los animales (identificados por caravanas) ocuparon las columnas, los cuatro períodos constituyeron las filas, y los distintos niveles de SA los tratamientos a suministrar, cuatro en total: uno que ofició de testigo (alimentado solamente con heno) y tres sujetos mantenidos con heno y cantidades crecientes de SA $(0,6 ; 1,2$ y $1,8 \mathrm{~kg} /$ día), a partir de ahora denominados "tratamientos cero, bajo, medio y alto". La asignación de los tratamientos a los animales se realizó al azar al comienzo del experimento.

El tiempo de duración de cada período fue de 21 días, intercalados con 13 días que obraron como etapa de adaptación a la nueva ración y para evitar la posible influencia período-tratamiento. Los 8 días restantes se emplearon para la recolección de muestras de los distintos parámetros a valorar. El ensayo tuvo una duración de 84 días (4 períodos de 21 días cada uno). Al completar el conjunto de los cuatro períodos, se cumplió con el diseño, que requiere un total de 16 observaciones. Las muestras de fluido ruminal se obtuvieron el día 21.

Los sujetos experimentales utilizados fueron 4 novillos cruza cebú, dotados de fístula ruminal, de aproximadamente $375 \mathrm{~kg}$ de peso vivo al momento del ensayo, los que se dispusieron en corrales individuales que poseían una parte con techo (para proporcionar resguardo de las inclemencias climáticas) y otra sin él (para asegurar un contacto con la luz solar). Los mismos contaban con bebederos individuales, así como comederos que permitieron colocar el total de la oferta de pasto. El suplemento se ofreció en bandejas individuales, momentos antes de la entrega del heno. Las raciones se suministraron en una toma diaria por la mañana $(8 \mathrm{~h})$.

La dieta empleada contenía heno (rollo molido grueso de pasto estrella, Cynodon nlemfuens), con $3,7 \%$ de $\mathrm{PB} ; 68,56 \%$ de fibra detergente neutro (FDN); $46,77 \%$ de fibra detergente ácido (FDA) y $8,1 \%$ de lignina, siendo ofertada ad libitum y completada con cantidades crecientes de SA (19,5\% de PB; $55,47 \%$ de FDN; $40,6 \%$ de FDA y $18,90 \%$ de extracto etéreo, EE), además de una mezcla mineral balanceada comercial. El día 1 de cada período, se procedió al registro de peso de cada animal (con una balanza digital móvil individual) a fin evaluar la evolución de los tratamientos. El contenido ruminal de cada animal se recolectó usando un método tradicional de extracción ${ }^{10}$, a diferentes horas posteriores a la ingesta del suplemento y heno (muestra preliminar a las 7 AM y luego a las 2, 4, 8, 12, 15 y $18 \mathrm{~h})$.

Para la valoración del $\mathrm{pH}$ ruminal, se recolectaron aproximadamente $150 \mathrm{ml}$ de fluido, directamente del 
rumen, en recipientes plásticos de boca ancha, en los que se sumergió el electrodo de un peachímetro portátil (Corning M90, Corning Inc, NY). Se obtuvieron un total de 112 registros de $\mathrm{pH}$ (4 períodos, 4 animales, 7 horas o momentos de registro). Para el dosaje de AGV, el fluido ruminal fue acondicionado para su transporte, con $8 \mathrm{ml}$ de ácido metafosfórico al $20 \%$, por cada $40 \mathrm{ml}$ del filtrado, en un recipiente plástico hermético, debidamente identificado y luego congelado a $-20^{\circ} \mathrm{C}$ hasta su análisis. Se obtuvieron 64 muestras para la estimación de AGV (4 períodos, 4 animales y 4 momentos de muestreo), que fueron analizados por cromatografía (cromatógrafo de fase gaseosa Perkin Elmer Autosystem XL Norwalk CT).

Para el análisis de amonio, el líquido ruminal filtrado fue acidificado con $2 \mathrm{ml}$ de ácido sulfúrico al $40 \%$ por cada $40 \mathrm{ml}$ y transferido a un recipiente de plástico hermético, debidamente rotulado, para ser congelado a $-20^{\circ} \mathrm{C}$ hasta su análisis. Se obtuvieron 112 muestras para valoración de amonio ruminal (4 períodos, 4 animales y 7 momentos de muestreo), el cual se determinó por la técnica Kjeldahl semi-micro.

Las muestras de contenido ruminal para determinar la cantidad y tipo de protozoarios, se obtuvieron de acuerdo a procedimientos clásicos ${ }^{18}$. A $20 \mathrm{ml}$ del fluido colectado se le adicionaron $20 \mathrm{ml}$ de una solución conservante-fijadora ( $\mathrm{NaCl} 9 \mathrm{~N}$ más formol al $40 \% \mathrm{a} / \mathrm{a}$ ), la cual fue envasada en un tubo de ensayo con tapón de goma y conservada bajo refrigeración hasta el momento de su uso. Se obtuvieron 80 muestras para el recuento de protozoos ruminales (4 períodos, 4 animales y 5 momentos de muestreo). El recuento y la determinación del género se realizaron por microscopía óptica según técnica $a d h o c^{22}$, registrándose las imágenes mediante una cámara digital Kodak Easy Share C653 3X/6,1 MP.

Los datos fueron analizados bajo un diseño de cuadrado latino balanceado $4 \times 4$ usando el procedimiento GLM del programa SAS. La suma de los cuadrados permitió la separación de los efectos animal-tratamiento. El efecto tratamiento definió la influencia de los distintos niveles de SA y el efecto animal consideró el impacto del factor individual. El efecto período definió la influencia del tiempo. Se realizaron contrastes ortogonales para estimar los efectos lineales, cuadráticos y cúbicos (nivel de semilla de algodón en el suplemento sobre todas la variables). Estos efectos determinaron la tendencia que adoptaron las medias de los tratamientos, para cada variable considerada.

Las variables ruminales se trataron como medidas repetidas y fueron analizadas como parcelas divididas con la opción Repeated del SAS, que incluye la corrección de Greenhouse-Geiser para los grados de libertad que involucren a los tests de F donde se prueba el efecto tiempo. La prueba de comparaciones múltiples de Duncan fue utilizada para confrontar par-a-par las medias que hubieran obtenido significación estadística $(\mathrm{p} \leq 0,05)$ en el análisis de la variancia.

\section{RESULTADOS Y DISCUSIÓN}

Los resultados obtenidos señalan que los diferentes niveles de SA (efecto tratamiento), no modificaron el $\mathrm{pH}$ ruminal de los animales bajo ensayo. El promedio de $\mathrm{pH}$ por tratamiento fue de 6,52 para el nivel alto de suplementación, 6,47 para el nivel medio, 6,38 para el nivel bajo y de 6,59 para el nivel cero. No se detectó interacción de tratamiento por hora de muestreo. El valor medio de $\mathrm{pH}$ ruminal de todos los tratamientos fue de 6,49; el cual se ubicó dentro de los rangos de referencia establecidos para este parámetro ruminal: 5,5 a $6,6^{26} \mathrm{y}$ 6 a $7^{6,28}$.

El análisis estadístico reveló una tendencia del efecto tiempo de muestreo (hora de toma de muestra) a la hora 8 post suplementación $(p=0,07)$. Los contrastes ortogonales aplicados señalaron una tendencia cuadrática significativa a las 8 horas $(p=0,03)$. En la Figura 1 se exhibe la evolución del $\mathrm{pH}$ ruminal de acuerdo al tratamiento. En la gráfica puede observarse que el tratamiento cero mantuvo el rango de $\mathrm{pH}$ más estable que los registrados en los tratamientos que recibieron suplementación con SA.

El efecto positivo de la inclusión de alimentos con alto tenor de fibra efectiva sobre el tiempo diario de rumia se traduce en una mejora sustancial de los valores de $\mathrm{pH}$ ruminal de los animales ${ }^{28}$. En el presente trabajo, debido al consumo ad libitum de heno y a la incorporación de SA entera sin procesamiento, el contenido de fibra no manifestó ser una limitante desde el punto de vista del estímulo de la rumia, lo que se habría manifestado en los valores de $\mathrm{pH}$ registrados.

La incorporación a la ración de semillas oleaginosas como SA ${ }^{17}$, canola ${ }^{14} \mathrm{y}$ sus derivados industriales ${ }^{24}$ no afectarían los valores de $\mathrm{pH}$ ruminal, aseveraciones que coinciden con lo observado en nuestra experiencia. Otras formas de aporte de fuentes de lípidos a la ración, como aceites vegetales ${ }^{3,27}$ o grasa animal ${ }^{3}$ mostraron similares resultados. El pH ruminal desempeña un importante papel en la modificación de las grasas a nivel del rumen ${ }^{23}$. Por su parte, los carbohidratos incorpo-

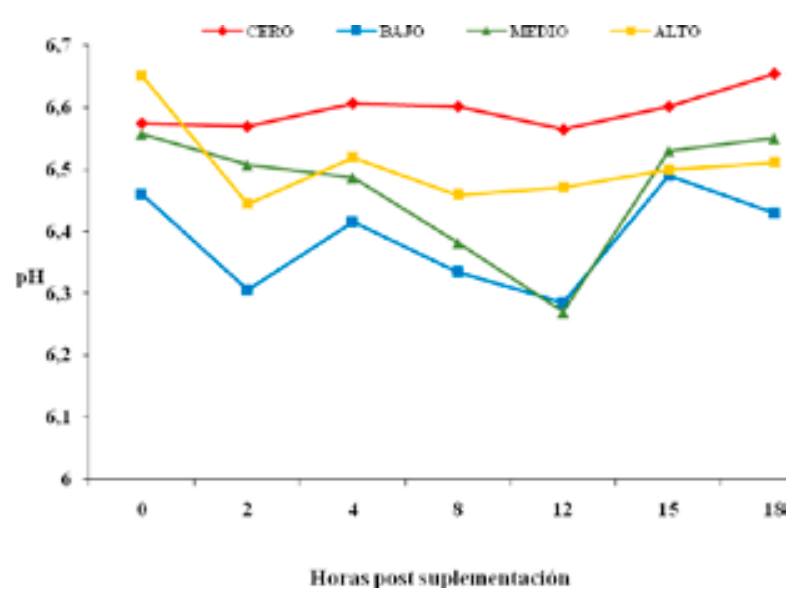

Figura 1. Evolución del pH ruminal de acuerdo a diferentes niveles de incorporación de SA a la ración. 
Tabla 1. Porcentajes de AGV con respecto a la concentración total.

\begin{tabular}{lcccc}
\hline \multirow{2}{*}{ ácidos grasos } & \multicolumn{4}{c}{ niveles de SA según tratamiento } \\
& cero & bajo & medio & alto \\
\hline AGV totales (mmol/1) & 78,50 & 76,58 & 81,26 & 73,68 \\
acético (\%) & 76,04 & 73,36 & 73,25 & 73,36 \\
propiónico (\%) & 15,14 & 16,27 & 17,23 & 17,27 \\
butírico (\%) & 5,91 & 6,86 & 6,06 & 5,51 \\
isobutírico (\%) & 1,89 & 1,75 & 1,73 & 1,86 \\
valérico (\%) & 0,29 & 0,45 & 0,44 & 0,48 \\
isovalérico (\%) & 0,92 & 1,23 & 1,24 & 1,45 \\
caproico (\%) & 0,04 & 0,07 & 0,05 & 0,02 \\
total (\%) & 100 & 100 & 100 & 100 \\
\hline
\end{tabular}

rados a la ración de rumiantes, podrían provocar marcados descensos del $\mathrm{pH}$ ruminal ${ }^{1,5,9}$.

En la Tabla 1 se consignan los porcentajes de cada AGV en particular, teniendo en cuanta la concentración total de AGV, para cada tratamiento. Los AGV constituyen el principal suministro de energía para el metabolismo de los rumiantes, cubriendo cerca del $60 \%$ de sus necesidades energéticas. La estadística reveló una marcada influencia del tratamiento, sobre ciertas variables asociadas al perfil de AGV ruminales. Estadísticamente no fueron detectados efectos del tratamiento sobre la concentración ruminal de AVG totales. Los promedios de la concentración total de AGV por tratamiento fueron de $81,25 \mathrm{mmol} / 1$ para el nivel medio de suplementación, 78,50 mmol/1 para el nivel cero, 76,76 $\mathrm{mmol} / \mathrm{l}$ para el nivel bajo y 73,67 para el nivel alto. La bibliografía cita como proporciones de referencia para los ácidos acético, propiónico y butírico rangos de 70:20:10 para dietas con alta proporción de forraje y de hasta 60:30:10 en dietas con alto contenido en granos y concentrados ${ }^{6,9}$.

Las relaciones promedio entre los ácidos acético, propiónico, butírico y los demás AGV ruminales evaluados en el presente trabajo (isobutírico, valérico, isovalérico y caproico) fueron de 73:18:6:3 para los tratamientos alto y medio; de 74:16:7:3 para el tratamiento bajo y de 76:15:6:3 para el tratamiento cero. Como pude observarse, las mismas tuvieron un valor de acetato superior a las citadas por la bibliografía, fenómeno que posiblemente se haya debido al aporte extra de FDA y FDN generado por la incorporación de SA a la ración, conclusión que coincide con observaciones de otros autores ${ }^{17}$. El tratamiento cero presentó el tenor más elevado de acetato, resultado previsible habida cuenta que el heno suministrado a los animales fue obtenido de una gramínea $\mathrm{C}_{4}$ (pasto estrella, Cynodon nlemfuensis) de mala calidad ${ }^{28}$, a fin de representar fielmente al campo natural imperante en la región, en épocas de déficit invernal.

Coincidentemente, otros investigadores aseveran que por su elevado porcentaje de fibra bruta, el empleo de SA en raciones debería ocasionar aumentos de la concentración molar de acetato ruminal ${ }^{17}$. Se han hallado mayores concentraciones de acetato al incorporar a la ración SA sin procesamiento (con cubierta: mayor tenor de fibra), que al emplear SA con distintos tipos de procesamiento ${ }^{2}$. En la presente experiencia, el menor porcentaje promedio de acetato se registró en el tratamiento alto $(54,04 \%)$, en relación a los tratamientos cero $(59,692 \%)$, bajo $(56,172 \%)$ y medio $(59,52 \%)$, circunstancia que podría deberse al menor consumo de heno registrado en el tratamiento alto.

Una mayor relación acetato:propionato fue registrada en el tratamiento cero (sin suplementación) con respecto a los tratamientos que recibieron diferentes niveles de SA (bajo, medio y alto) a lo largo de todas las horas de muestreo. No se detectó interacción de tratamiento por hora de muestreo. Los contrastes ortogonales aplicados revelaron una tendencia lineal ascendente significativa desde el tratamiento cero hacia el alto, para los valores de ácido propiónico a las 4 horas post suplementación, $(\mathrm{p}=0,004)$.

La relación acetato:propionato reveló una tendencia lineal descendente significativa en todos los horarios de muestreo. En las horas 4, 8 y 12 post suplementación también pudo observarse una tendencia cuadrática significativa. Este comportamiento de la relación acetato:propionato indica un mayor porcentaje de ácido acético (no significativo) en los niveles cero $(59,69 \%)$ y medio $(59,52 \%)$, en relación al bajo $(56,17 \%)$ y alto $(54,04 \%)$. El efecto tratamiento modificó significativamente los valores del ácido propiónico a las 4 horas post suplementación $(\mathrm{p}=0,019)$; los valores mínimos de este AGV fueron registrados en el nivel cero. En otros trabajos se obtuvieron significativas disminuciones de acetato y aumentos significativos de propionato, al incrementar los niveles de inclusión de SA en la ración ${ }^{1}$, en coincidencia con los resultados aquí obtenidos. En otros casos se registraron aumentos de la proporción ruminal de propionato al aumentar la incorporación de SA o grasas a la ración ${ }^{15}$. Un marcado incremento de propionato y butirato ocurre al incrementar los niveles de inclusión de concentrados a la ración ${ }^{9}$.

La concentración del ácido butírico fue afectada por el tratamiento a las $4 \mathrm{~h}(\mathrm{p}=0,05)$ y $8 \mathrm{~h}(\mathrm{p}=0,016)$ post suplementación. Los valores máximos se registraron en los tratamientos bajo y medio, con respecto al cero y alto. Los contrastes ortogonales revelaron una tendencia cuadrática significativa para este AGV, a las $4 \mathrm{~h}(\mathrm{p}=0,045)$ y $8 \mathrm{~h}(\mathrm{p}=0,039)$ post suplementación. Los productos finales de la fermentación de los carbohidratos son principalmente los ácidos acético, propiónico y butírico. La fermentación de proteínas produce estos ácidos junto con ácido valérico (que tiene una cadena de 5 carbonos) y los ácidos ramificados (isoácidos) isobutírico e isovalérico. Estos AGV adicionales suman menos del $5 \%$ del total ruminal ${ }^{26}$. En el presente trabajo, dichos ácidos grasos constituyeron el 3\% de la proporción total.

Una mayor cantidad de concentrado enriquecido con aceite de linaza en la dieta, disminuyó la proporción de iso-valerato y acetato, pero aumentó el nivel de propionato y valerato; además se observó interacción 
entre los valores de ácido caproico, la relación forraje:concentrado y la suplementación con aceite de linaza. La suplementación con aceite vegetal aumentó el propionato pero disminuyó al n-butirato ${ }^{27}$.

En la Figura 2 se presentan las variaciones de los porcentajes parciales de cada AGV con respecto a la concentración total. Los mayores porcentajes de ácidos valérico e isovalérico se registraron en los tratamientos que recibieron SA como suplemento. Aumentos en la inclusión de grasa en la ración de bovinos ocasionan una disminución en la concentración de AGV totales ${ }^{14}$, comportamiento que si bien fue observado en el presente trabajo, no fue estadísticamente significativo.

Otros autores no registraron modificaciones en la concentración total y/o en el perfil de AGV ruminales con la incorporación de SA en la ración 1,15, 17 . Aquí, la concentración total de AGV promedio de los animales que recibieron SA como suplemento fue de 73,678 $\mathrm{mmol} / 1$ para el nivel alto, de $81,256 \mathrm{mmol} / 1$ para el nivel medio y de $76,757 \mathrm{mmol} / \mathrm{l}$ para el nivel bajo, todos ellos significativamente más elevados que los citados por otros autores ${ }^{2}$ para las tres formas de procesamiento de la SA empleada en su trabajo.

La incorporación de lípidos a la ración en forma de grasa animal o aceite vegetal tampoco generaría variaciones en la concentración de AGV totales ${ }^{3,27}$. La concentración del amonio ruminal difirió significativamente entre los tratamientos en todas las horas de muestreo, a excepción de la hora 12 post suplementa-

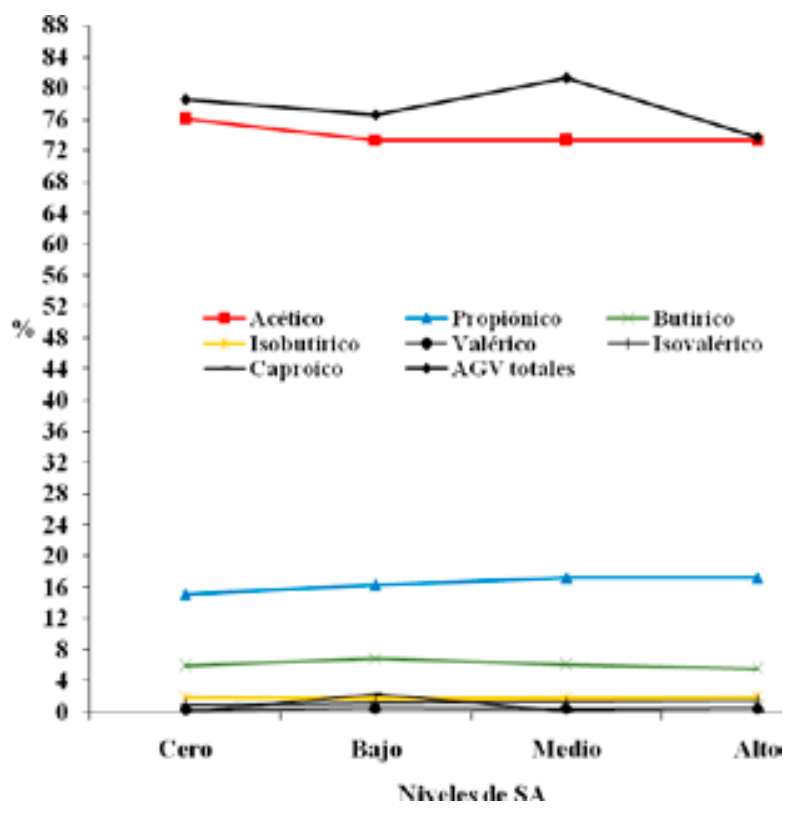

Figura 2. Comportamiento de los AGV según tratamiento. ción, donde sólo se observó una tendencia incrementativa $(\mathrm{p}=0,084)$. Las reservas de $\mathrm{N}$ amoniacal ruminal son extremadamente dinámicas y dependen de la degradación de compuestos nitrogenados proteicos y no proteicos y del reciclaje de urea por intermedio de la saliva del animal ${ }^{6,28}$.

En la Tabla 2 y Figura 3 se exponen las variaciones en los niveles de $\mathrm{N}$ amoniacal ruminal. Los valores superiores de amonio ruminal se registraron en el tratamiento alto, disminuyendo en forma lineal hacia los tratamientos medio, bajo y cero, siendo este último el que presentó menores valores de N-NH3 a lo largo de toda la experiencia. Los niveles medio y bajo de suplementación fueron los que presentaron mayores fluctuaciones en el rango de amonio ruminal a lo largo de las diferentes horas de muestreo. Fue coincidente, a la hora 15 post comida, el registro del menor nivel de amonio ruminal en los tres tratamientos que recibieron suplementación con SA. No se detectó interacción de tratamiento por hora de muestreo. Los contrastes ortogonales mostraron una significativa tendencia lineal ascendente en todas las horas de registro.

Para no generar limitaciones de la síntesis microbiana, la concentración mínima de $\mathrm{N}_{2}$ amoniacal debería ser $50 \mathrm{mg}$ de $\mathrm{N}-\mathrm{NH}_{3} / 100 \mathrm{ml}$ de líquido ruminal ${ }^{6}$. Otros autores han obtenido valores medios de $8,5 \mathrm{mg}$

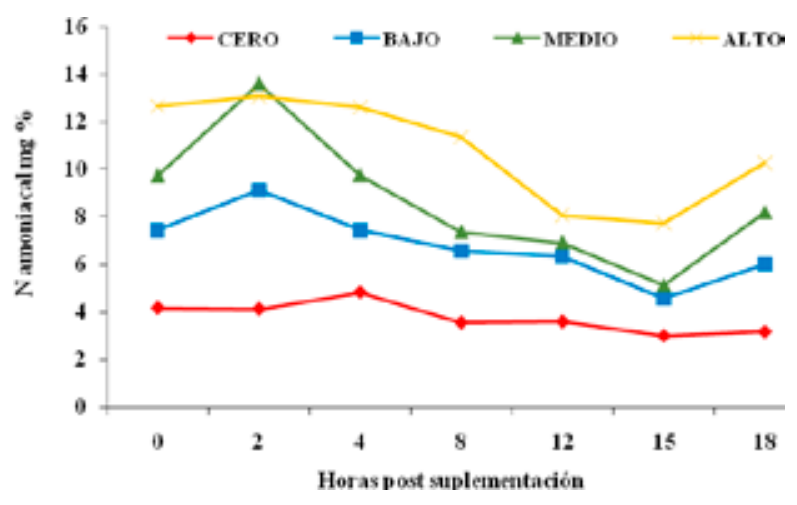

Figura 3. Niveles de amonio ruminal según tratamiento. 
de $\mathrm{N}-\mathrm{NH}_{3} / 100 \mathrm{ml}$ de líquido ruminal, variando de 3,1 a $14,5 \mathrm{mg}$ de $\mathrm{N}-\mathrm{NH}_{3} / 100$ $\mathrm{ml}$, al suplementar bovinos con fuentes de $\mathrm{N}$ y almidón de diferente degradabilidad ruminal ${ }^{11}$. En el transcurso de las primeras horas se han registrado valores máximos de amonio de 7,52 a 29,84 $\mathrm{mg}$ de $\mathrm{N}-\mathrm{NH}_{3} / 100 \mathrm{ml}$ al emplear raciones conteniendo expeller de algodón y urea respectivamente ${ }^{20}$. Las concentraciones ruminales de nitrógeno amoniacal ( $\overline{\mathrm{x}}: 29,9 \mathrm{mg} / \mathrm{dl})$ no difirieron al incorporar distintos tipos de subproductos de semillas oleaginosas a la ración de bovinos ${ }^{1}$.

En nuestra experiencia los valores medios de amonio fueron de 10,$847 ; 8,671$ y $6,801 \mathrm{mg}$ de $\mathrm{N}-\mathrm{NH}_{3} / 100$ $\mathrm{ml}$ de líquido ruminal para los niveles alto, medio y bajo de suplementación con SA respectivamente, siendo de $3,781 \mathrm{mg}$ de $\mathrm{N}-\mathrm{NH}_{3} / 100 \mathrm{ml}$ para el tratamiento cero (solo heno). En relación a los valores de referencia citados por la bibliografía, sólo el tratamiento cero de suplementación presentaría valores limitantes de $\mathrm{N}$ ruminal. El tratamiento alto se encontraría en la media de los valores mencionados por otros autores. Por su parte, el tiempo en que se registraron los aumentos de las concentraciones de $\mathrm{N}_{2}$ amoniacal varió entre tratamientos.

En otras publicaciones se reportó que los picos en la concentración de $\mathrm{N}_{2}$ amoniacal ocurrieron a las 2 horas post alimentación y presentaron un valor medio de $14,3 \mathrm{mg}$ de $\mathrm{N}-\mathrm{NH}_{3} / 100 \mathrm{ml}$, al recibir los animales como suplemento fuentes de almidón y $\mathrm{N}$ de alta y baja degradabilidad ${ }^{11}$. En coincidencia con lo afirmado en dicho trabajo, los tratamientos alto, medio y bajo registraron aquí sus mayores concentraciones a las 2 horas post suplementación.

En otras investigaciones el valor medio mínimo de $\mathrm{N}_{2}$ amoniacal registrado fue de $4,0 \mathrm{mg} / 100 \mathrm{ml}$ de líquido ruminal, a la hora 6 post suplementación ${ }^{11}$. En la presente experiencia, los valores mínimos de amonio para todos los tratamientos fueron observados a la hora 15 post suplementación, siendo de 7,750; 5,125; 4,600 y de $3,000 \mathrm{mg}$ de $\mathrm{N}-\mathrm{NH}_{3} / 100 \mathrm{ml}$, para los niveles alto, medio, bajo y cero de suplementación respectivamente. El valor medio citado por dichos autores se aproxima al registrado para los tratamientos bajo y cero de este ensayo.

La postergación en el tiempo de aparición de los valores mínimos de amonio en los tratamientos que recibieron suplementación, puede aquí atribuirse al tipo de proteínas que aporta la SA a la ración (de lenta degradabilidad ruminal), en comparación a las empleadas por otros autores. Otra posible razón del retardo, puede deberse a la falta de fuentes de aporte de energía que presentaban las raciones empleadas en nuestro trabajo, que harían que perdure por más tiempo el $\mathrm{N}_{2}$ a nivel ruminal (más manifiesto en el tratamiento alto). Otros usaron fuentes de energía de alta y baja degradabilidad ruminal ${ }^{11}$.

El $\mathrm{N}_{2}$ ruminal se incrementa con el empleo de SA en las raciones de bovinos, reflejando una mayor degradabilidad de la proteína que incorpora ${ }^{1,15}$. Estos resultados fueron similares a los observados en la presente experiencia, donde los niveles más elevados de $\mathrm{N}_{2}$ amoniacal fueron registrados en los animales que recibieron suplementación con SA. Se sostiene que la grasa incorporada a la ración no reduce la síntesis de proteína microbiana en el rumen ${ }^{6}$. Los incrementos en los niveles de suplementación proteica elevan la concentración de amonio ruminal. Los valores promedio de $\mathrm{N}_{2}$ amoniacal en el líquido ruminal registrados en la presente experiencia $(3,78 ; 6,80 ; 8,67$ y $10,84 \mathrm{mg} / \mathrm{dl}$ para los tratamientos cero, bajo, medio y alto, respectivamente) fueron significativamente inferiores a los citados en otros reportes ${ }^{15}$.

La concentración total de protozoos fue mayor en el tratamiento cero a lo largo de todas las horas de muestreo. En los animales que recibieron suplementación con SA (niveles bajo, medio y alto) se registraron menores recuentos de ciliados. A cada aumento de SA en el suplemento, se registró un descenso lineal del recuento total.

La cantidad de protozoos en el rumen del bovino es de $10^{5}$ a $10^{6}$ células $/ \mathrm{ml}$ de contenido ruminal. El papel de los protozoos del rumen se ha centrado en su comportamiento depredador ${ }^{16}$, siendo retenidos en el rumen, limitando su flujo hacia el duodeno ${ }^{30}$. No se detectó interacción de tratamiento por hora de muestreo.

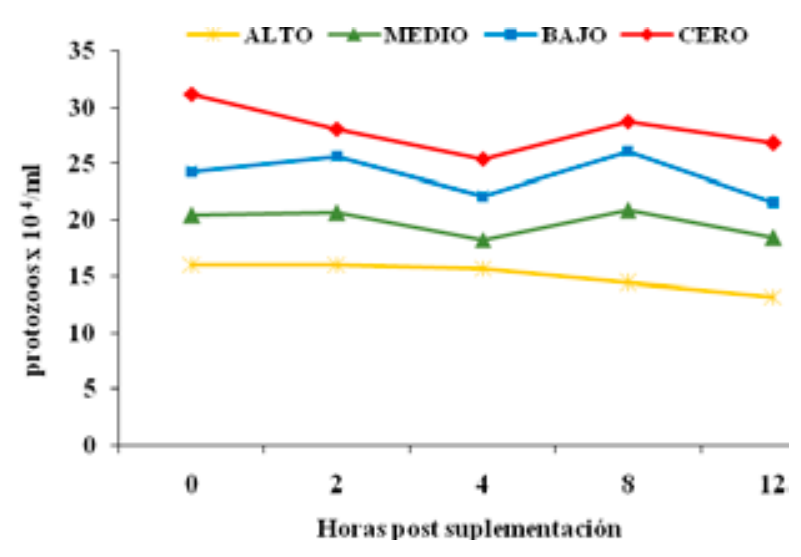

Figura 4. Evolución del recuento de protozoarios de acuerdo a los niveles de incorporación de SA a la ración. 
En la Tabla 3 se expone la evolución del recuento total de protozoos de acuerdo al tratamiento y a las horas de muestreo post suplementación.

Una compilación de las variables que influirían sobre la concentración de protozoario ruminales es extremadamente difícil de realizar, pero básicamente se resumiría en el tipo de alimentación, el nivel de consumo, la hora del día en que ingiere alimento, el tiempo (hora de muestreo) y el número de comidas diarias, además de la especie animal, la estación del año y la ubicación geográfica, lo que hace que todas las comparaciones sean algo cuestionables ${ }^{7}$.

El tratamiento afectó significativamente los porcentajes de las diferentes familias y géneros de protozoarios ruminales. Para algunos, la densidad varía de acuerdo a los géneros y especies de ciliados: $3 \times 10^{4}$ protozoos/ml para los género Entodinium, Dasytricha y Diplodinium, y 1 × $10^{4}$ protozoos $/ \mathrm{ml}$ para Isotricha y Epidinia ${ }^{28}$. Los resultados aquí obtenidos coinciden con los citados por este autor. El género Entodinium se presentó en valores que fueron de $1,7 \times 10^{5} / \mathrm{ml}$ para el tratamiento cero (sin SA) y de $1,3 \times 10^{5} / \mathrm{ml}, 1,2 \times 10^{5} /$ $\mathrm{ml}$ y $1,1 \times 10^{5} / \mathrm{ml}$ para los tratamientos medio, bajo y alto, respectivamente. En la Figura 4 se representa la evolución del recuento total de protozoarios de acuerdo al tratamiento con diferentes niveles de SA.

El porcentaje de la familia de holotricos fue significativamente mayor en el tratamiento cero en todos horarios de muestreo, excepto en la hora 0 (tendencia $\mathrm{p}=$

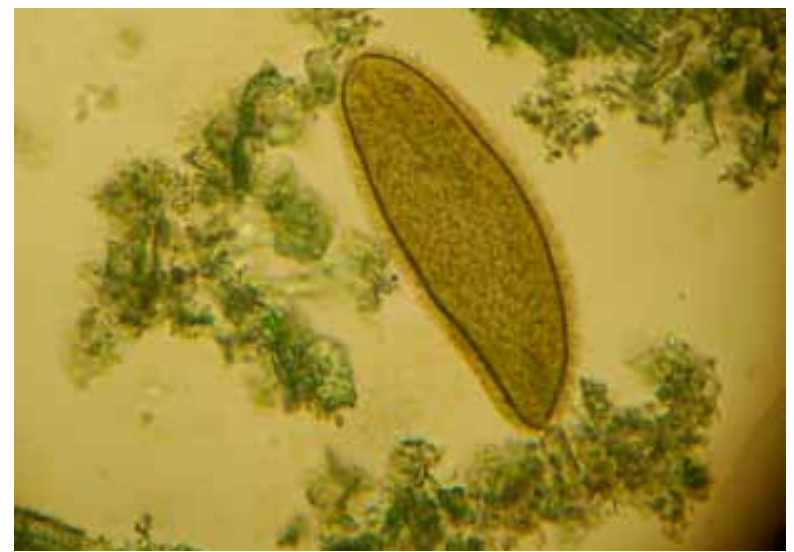

Figura 5. Protozoo del género Isotricha (160x).

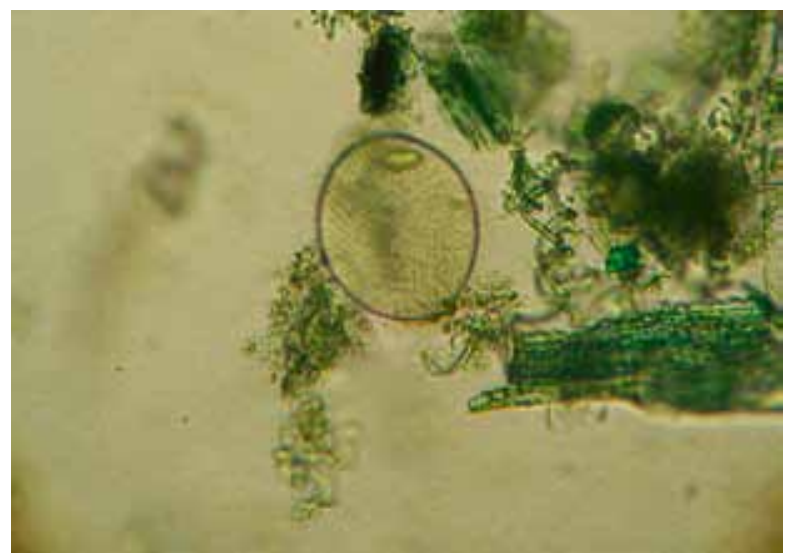

Figura 6. Protozoo del género Dasytricha (160x).

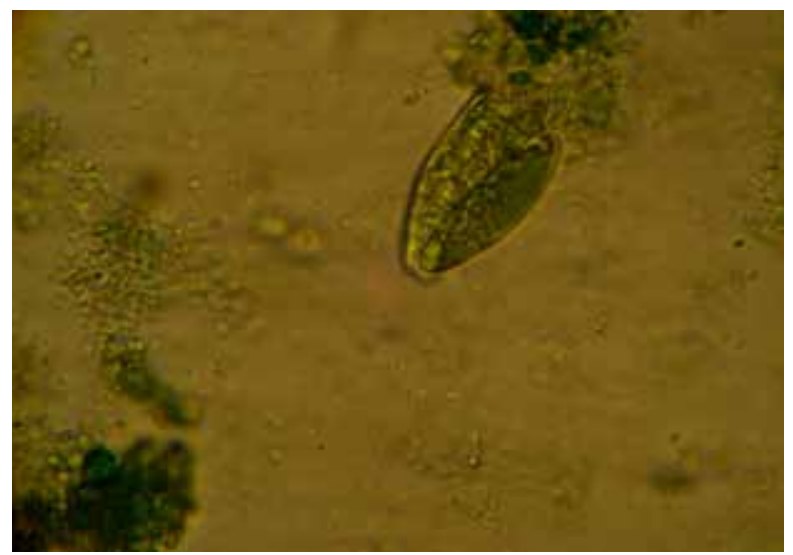

Figura 7. Protozoo del género Entodinium (400x).

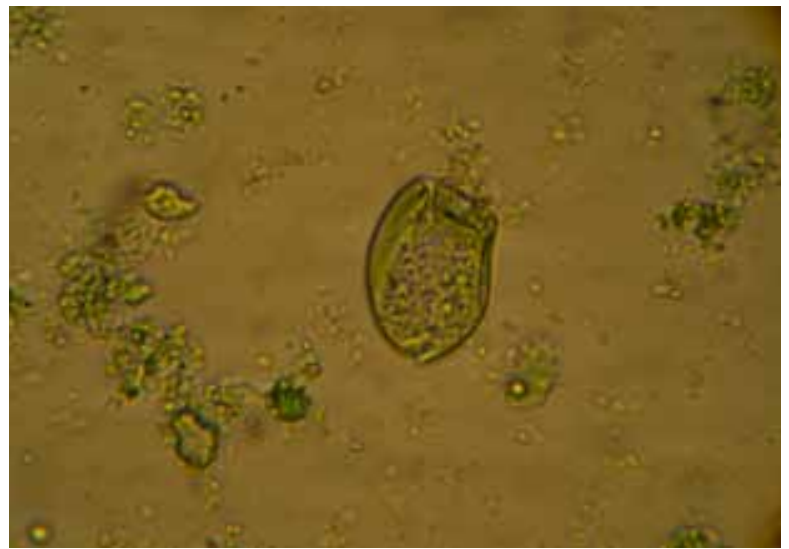

Figura 8. Protozoo del género Entodinium (400x).

$0,07)$ con respecto a los tratamientos bajo, medio y alto. Los géneros Dasytrica e Isotricha, (Figuras 5 y 6, respectivamente) presentaron un comportamiento similar; sus porcentajes fueron significativamente mayores en el tratamiento cero y decrecieron linealmente hacia los tratamientos bajo, medio y alto. Ambos géneros predominaron con significancia estadística en todas las horas post suplementación, excepto en la hora 0 (ayunas), donde el género Dasytricha no manifestó diferencia estadística y el género Isotricha sólo una tendencia ( $\mathrm{p}$ $=0,066$ ). El género Isotricha se presentó en mayor porcentaje que el género Dasytricha a lo largo de todas las horas de muestreo.

El porcentaje de protozoarios pertenecientes a la familia Oligotricha se reveló significativamente más elevado en todos los horarios de muestreo, a excepción de la hora 0 , donde sólo manifestó una tendencia ( $\mathrm{p}$ $=0,063)$. El tratamiento alto fue el que, en promedio, ostentó mayores niveles de esta familia de protozoos $(98,4 \%)$ decreciendo linealmente hacia los tratamientos medio $(92,15 \%)$, bajo $(85 \%)$ y cero $(75,8 \%)$.

Al considerar los diferentes géneros en particular, las modificaciones variaron de acuerdo a las horas de toma de muestras, posteriores a la suplementación. El género Entodinium (Figuras 7 y 8 ) fue el significativamente predominante en todas las horas del día; asimismo fue el género predominante en todos los tratamientos. Esta superioridad se manifestó en los promedios por tratamiento, en donde el nivel alto de suplemen- 


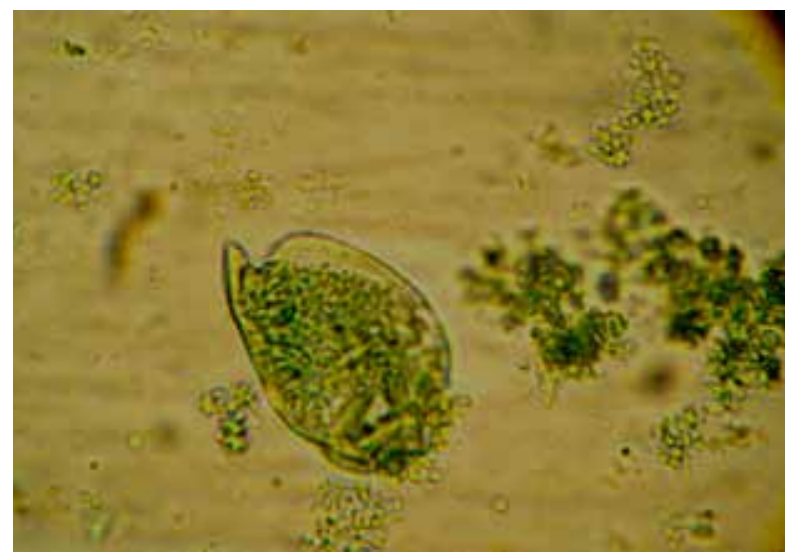

Figura 9. Protozoo del género Diplodinium (400x).

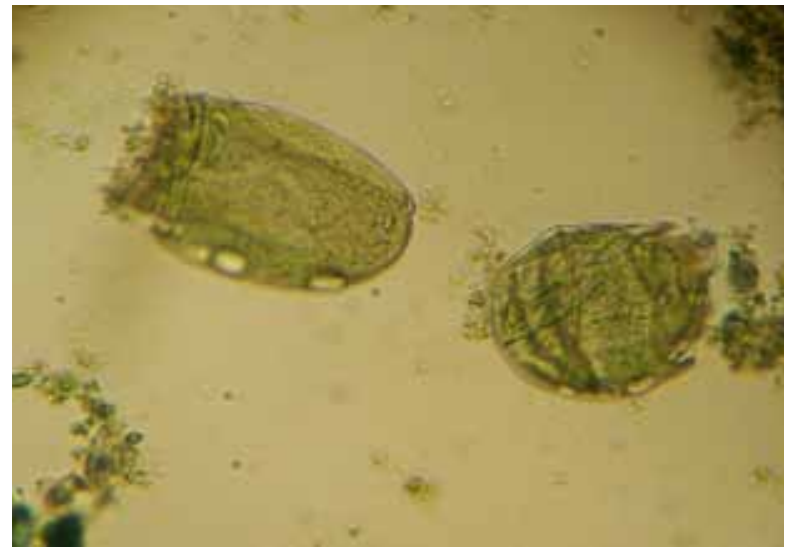

Figura 10. Protozoos del género Ostracodinium (160x).

tación, registró porcentajes superiores $(74,95 \%)$ con respecto a los niveles medio $(54,40 \%)$, bajo $(46,80 \%)$ y cero $(43,45 \%)$.

El género Diplodinium (Figura 9) fue el dominante, en promedio, en los tratamientos bajo y medio $(21,15$ y $21,45 \%)$ con respecto al alto y cero $(15,25$ y $16,3 \%)$. Esta diferencia se manifestó de manera significativa en la hora $0(\mathrm{p}=0,05)$ y reveló una tendencia $(\mathrm{p}=0,06) \mathrm{a}$ la hora 12 post suplementación.

El género Ostracodinium (Figura 10) prevaleció, en promedio, en el tratamiento cero $(37,45 \%)$ con respecto al bajo $(16,10 \%)$ y medio $(15,50 \%)$ y aún más en comparación al nivel alto (7,15\%). Esta diferencia se manifestó de manera significativa $(\mathrm{p}=0,03)$ a la hora 2 post comida, donde el nivel cero presentó un porcentaje superior de este género $(17,50 \%)$ con relación a los niveles bajo (15,75\%), medio (13\%) y cero $(5,5 \%)$. A la hora 12 post suplementación, el porcentaje de este género de protozoarios predominó significativamente $(\mathrm{p}=$ $0,05)$ en los tratamientos bajo $(16 \%)$ y medio $(13,35 \%)$, en relación al cero $(12 \%)$ y alto $(9,25 \%)$.

Los contrastes ortogonales aplicados señalaron una significativa tendencia lineal descendente desde el tratamiento cero hacia el alto en los porcentajes de la familia Holotricha, así como de los géneros Dasytricha e Isotricha lo largo de todas las horas de registro. Por el contrario, los porcentajes de la familia Oligotricha y del género Entodinium, mostraron una significativa tendencia lineal ascendente desde el tratamiento cero hacia el alto, en todos los momentos de toma de muestras post suplementación.

El género Ostracodinium solo reveló una tendencia lineal significativa a las horas $2(\mathrm{p}=0,008)$ y $8(\mathrm{p}=$ $0,05)$ post suplementación. No se observaron modificaciones atribuibles al efecto período sobre las variables relacionadas a la concentración total y los porcentajes de familias y géneros de protozoarios ruminales. No se registraron influencias significativas del efecto animal sobre los protozoos ruminales.

En la Figura 11 se representan las modificaciones en el porcentaje de los géneros de protozoos ruminales atribuibles al tratamiento con diferentes niveles de suplementación con SA. Los protozoarios incluidos como "varios" fueron aquéllos que al momento del recuento no pudieron ser clasificados dentro de los géneros considerados más importantes; sus porcentajes no superaron -en promedio- el 1\% del recuento total.

Los protozoos ruminales adquieren relevancia para la síntesis endógena de ácido linoleico conjugado (CLA), al proporcionar las mayores cantidades de ácido vacénico, el cual se constituye como el precursor para la síntesis endógena; este aporte se da a través de mecanismos de incorporación de ácidos grasos insaturados y poliinsaturados en su biomasa microbiana y por su flujo al duodeno, ya que estos microorganismos, representarían la principal fuente de ácidos grasos asimilables por el rumiante ${ }^{30}$.

Otros autores registraron una marcada disminución de la concentración de amonio en el líquido ruminal (23\% menor) de los animales defaunados o con la población de ciliados reducida en relación al grupo control $^{21}$, lo cual es consistente con la reducción del reciclaje ruminal de $\mathrm{N}_{2}{ }^{6,28}$. Tales hallazgos no coinciden con lo registrado en la presente experiencia, donde los menores recuentos de ciliados ruminales fueron registrados en el nivel alto de suplementación con SA, que además ostentó las mayores concentraciones de amonio ruminal.

En otros trabajos ${ }^{1}$ se observó que cada aumento de SA y disminución de sorgo molido en el suplemento, se correspondieron con un descenso lineal del recuen-

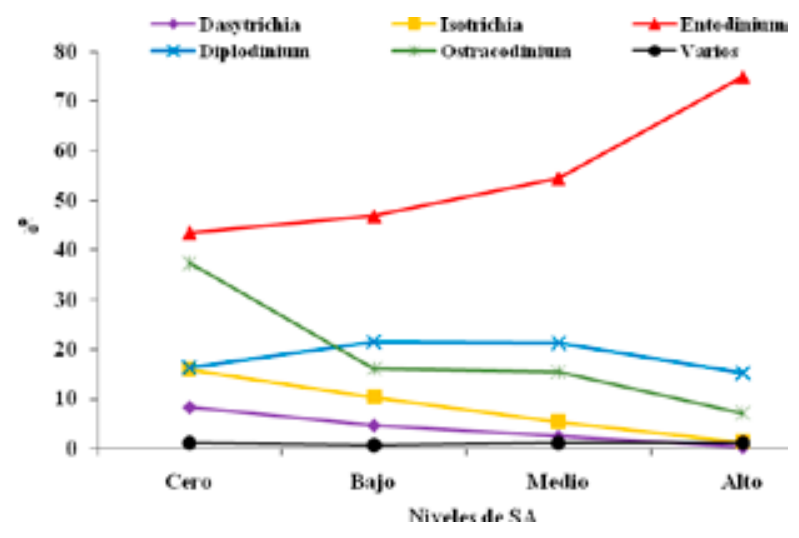

Figura 11. Evolución de los géneros de protozoarios de acuerdo al tratamiento. 
to total de protozoarios ruminales: 13,$51 ; 9,29 ; 6,47 \mathrm{y}$ 4,38 protozoos $\times 10^{4} / \mathrm{ml}$ para los tratamientos cero, bajo, medio y alto. Entodinium fue el género predominante en todos los tratamientos: cero $(90,77 \%)$, bajo $(91,31 \%)$, medio $(94,12 \%)$ y aAlto $(98,1 \%)$. A las 12 horas post alimentación, se registró una tendencia lineal ascendente para Entodinium y una tendencia lineal descendente para Isotricha. En otros casos fueron reportados menores recuentos de protozoos en animales que consumieron $\mathrm{SA}^{15}$. Una marcada disminución en el recuento total de protozoos fue encontrada al emplear aceite de lino como fuente de suplementación lipídica ${ }^{27}$.

El descenso del recuento total de protozoos cuando se emplean proporciones elevadas de SA como suplemento puede atribuirse a los ácidos grasos presentes en la misma, que serían tóxicos para los protozoos y las bacterias. Los AG insaturados son muy tóxicos para las bacterias gram-positivas (celulolíticas), bacterias metanogénicas y protozoos. Mientras los lípidos esterificados se encuentran principalmente en el fluido ruminal, los AGL se hallarían asociados a la superficie de las partículas ${ }^{4}$.

La disminución del número de protozoarios fue un hallazgo constante en numerosos estudios en los que se emplearon aceite de lino y otras fuentes de lípidos no saturados como suplemento para rumiantes, con reducciones que variaron entre 0 y $74 \%{ }^{8}$. Otros investigadores verificaron una gran disminución de la población de protozoos al emplear aceite mezcla de cocina, como aporte de lípidos y agente defaunante, en bovinos ${ }^{25}$. Los pequeños protozoos hallados fueron principalmente del género Entodinium y los grandes ciliados fueron principalmente Polyplastron y holotricos.

Los efectos tóxicos de los aceites insaturados sobre la actividad microbiana nunca quedaron claramente demostrados ${ }^{12}$. Otro factor al que también podría atribuirse el descenso del recuento de protozoos, sería el contenido de gosipol presente en la SA ${ }^{13}$. A este compuesto polifenólico se le asignan propiedades antimicrobianas, que se han descrito sobre microorganismos ruminales como Lactobacillus sp. Para algunos especialistas, los protozoos ruminales serían trascendentales en el metabolismo lipídico de los rumiantes ${ }^{30}$.

Como conclusión podría afirmarse que los resultados obtenidos acrecientan el acervo de la fisiología ruminal y posibilitan la comprensión del mecanismo de acción de la SA como suplemento nutricional de los bovinos. Se demuestra que ninguno de los diferentes niveles de inclusión de SA en la ración fueron capaces de modificar significativamente el $\mathrm{pH}$ ruminal. El empleo de esta semilla oleaginosa no afectó la concentración de AGV totales del rumen, aunque aumentó el propionato y disminuyó el acetato (disminuyendo la relación acetato:propionato), sin variación del isobutirato. El ácido butírico se elevó en los tratamientos bajo y medio; los ácidos valérico e isovalérico aumentaron por el suministro de SA y el ácido caproico declinó en los tratamientos alto y bajo. El amonio ruminal $\left(\mathrm{N}_{-} \mathrm{NH}_{3}\right)$ reveló un aumento lineal paralelo a la incorporación de
SA a la dieta. El recuento de protozoarios totales disminuyó en función del aumento del suplemento. Entodinium prevaleció en todos los tratamientos, en tanto que Dasytrichia, Isotrichia y Ostracodinium predominaron en tratamiento cero y Diplodinium en los niveles bajo y medio de suplementación.

Agradecimientos. Al doctor Oscar Balbuena y al personal de las agencias del INTA de Colonia Benítez (Chaco), Mercedes (Corrientes) y Castelar (Buenos Aires, Argentina), por colaborar en el desarrollo del presente trabajo.

\section{REFERENCIAS}

1. Balbuena O, Arakaki CL, Kucseva CD, Velazco GA. 1999. Effects of levels of whole cottonseed in the supplement on performance, blood urea nitrogen and ruminal variables of grazing steers. J Anim Sci 29: 193-194.

2. Bernard JK Calhoun MC, Martin SA. 1999. Effect of coating whole cottonseed on performance of lactating dairy cows. J Dairy Sci 82:1296-1304.

3. Bock BJ, Harmon DL, Brandt RT, Schneider JE. 1991. Fat source and calcium level effects on finishing steer performance, digestion and metabolism. J Anim Sci 69: 22112224.

4. Broudiscou L, Pochet S, Poncet C. 1994. Effect of linseed oil supplementation on feed degradation and microbial synthesis in the rumen of ciliate-free and refaunated sheep. Anim Feed Sci Technol 49: 189-202.

5. Cannizzo C, Gianesella M, Giudice E, Messina V, Piccione G, Morgante M. 2012. Serum acute phase proteins in cows with SARA (Subacute Ruminal Acidosis) suspect. Arq Bras Med Vet Zootec 64: 5-22.

6. Church DC. 1993. El Rumiante. Fisiología digestiva y nutrición. Acriba, Zaragoza, $641 \mathrm{p}$.

7. Dehority BA, Orpin CG. 1997. Development of and natural fluctuations in rumen microbial populations. In: The rumen microbial ecosystem (Hobson PN, Stewart CS, ed.), Blackie Acad Prof, London, p. 196-220.

8. Doreau M, Ferlay A. 1995. Effect of dietary lipids on nitrogen metabolism in the rumen: a review. Livest Prod Sci 43: 97-110.

9. Dos Santos M, Oliveira SM; Primavesi O, Lima MA, Toyoko R, Berchielli TT. 2013. Methane emissions and estimates of ruminal fermentation parameters in beef cattle fed different dietary concentrate levels. Bras Zootec 42: 592-598.

10. Firkins JL, Berger LL, Merchen NR, Fhaey GC, Nelson DR. 1986. Effects of feed intake and protein degradability on ruminal characteristics and site of digestion in steers. J Dairy Sci 69: 2111-2123.

11. Fregadolli FL, Zeoula LM, Ferriani A, Nunes I, Ferreira S, Guimarães ZL, Kassies MP, Ortega A. 2001. Efeito das fontes de amido e nitrogênio de diferentes degradabilidades ruminais. 2. Ph, concentração de amônia no líquido ruminal e eficiência de síntese microbiana. Rev Bras Zootec 30: 1418-1423. 
12. Hudson WG, Frank JH, Castner JL. 1988. Biological control of Scapteriscus spp. mole crickets (Orthoptera: Gyllotalpidae) in Florida. Am Entomol 34: 192-198.

13. Ikwuegbu OA, Sutton JD. 1982. The effect of the amount of linseed oil supplementation on rumen metabolism in sheep. Br J Nutr 48: 365-375.

14. Khan M, Dolberg F, Akbar M. 1992. Effect of fishmeal and wheat bran diet on the performance of local lactating cows in Bangladesh. Bangladesh J Anim Sci 21: 37-42.

15. Keele JW, Roffler RE, Beyers KZ. 1989. Ruminal metabolism in no lactating cows fed whole cottonseed or extruded soybeans. J Anim Sci 67: 1612-1622.

16. Leng RA. 1982. Dynamic of protozoa in the rumen of sheep. Br J Nutr 48: 399-415.

17. Malcolm KJ, Kiesling HE 1990. Effects of whole cottonseed and live yeast culture on ruminal fermentation and fluid passage rate in steers. J Anim Sci 68: 1965-1978.

18. Martin C, Devillard E, Michalet B. 1999. Influence of sampling site on concentrations and carbohydrate-degrading enzyme activities of protozoa and bacteria in the rumen. J Anim Sci 77: 979-987.

19. McLennan SR, Plasto AW, Doogran VJ, Dillon RD. 1998. Whole cottonseed and cottonseed meal supplements for cattle given a hay based diet. Anim Product in Australia 22: 111-114.

20. Moraes AA, Figueiredo P, Marques R. 2000. Produção de amônia na fermentação in vitro de rações com levedura, ureía ou farelo de algodão. Rev Bras Zootec 29: 598-602.

21. Navas A, Cortes JE, Gutierrez EA. 1997. Efecto de la reducción de la población de protozoarios ciliados sobre el funcionamiento ruminal de ovinos alimentados con tamo de trigo. Arch Latinoam Prod Anim 5: 98-101.
22. Ogimoto K, Imai S. 1981. Atlas of rumen microbiology, Sci. Soc. Press, Tokio, $231 \mathrm{p}$.

23. Oliveira SG, Simas JM, Santos FA. 2004. Principais aspectos relacionados às alterações no perfil de ácidos graxos na gordura do leite de ruminantes. Arch Vet Sci 9: 73-80.

24. Santos VC, Ezequiel JM, Morgado ES, Homem AC, Fávaro VR, D'Aurea AP, Souza SF, Barbosa JC. 2012. Influência de subprodutos de oleaginosas sobre parâmetros ruminais e a degradação da matéria seca e da proteína bruta. Arq Bras Med Vet Zootec 64: 1284-1291.

25. Seng M, Preston TR, Leng RA, Meulen UT. 2001. Effect of a single drench of cooking oil on the rumen ecosystem and performance of young local "yellow" cattle fed rice straw and cassava foliage. Livest Res Rural Dev 13: 4.

26. Swenson MJ, Reece WO. 1999. Fisiología de los animales domésticos de Dukes, 2 da ed., Uthea, México, 925 p.

27. Ueda K, Ferlay A, Chabrot J, Loor JJ, Chilliard Y, Doreau M. 2003. Effect of linseed oil supplementation on ruminal digestion in dairy cows fed diets with different forage: concentrate ratios. J Dairy Sci 86: 3999-4007.

28. Van Soest PJ. 1994. Nutritional ecology of the ruminant, Cornell Univ Press, Ithaca, 476 p.

29. Wallace RJ, Czerkawski JW, Breckendrige G. 1981. Effect of monensin on the fermentation of basal rations in the rumen simulation technique. Br J Nutr 46: 131-137.

30. Zapata R, Gutiérrez LA, Polanco D. 2012. Papel de los protozoos ciliados ruminales en la síntesis de ácido linoleico conjugado. Rev Colomb Cienc Pec 25: 135-149. 